\title{
As tecnologias na educação: o papel da equipe gestora nas práticas pedagógicas
}

Technologies in education: the role of the management team in pedagogical practices

Givanildo da Silva

Doutor em Educação pela Universidade Federal da Paraíba. Professor Adjunto do Centro de Educação da Universidade Federal de Alagoas - Campus A. C. Simões, Maceió/Alagoas. Brasil. givanildopedufal@gmail.com

\section{Maria Aparecida Pereira Viana}

Doutora em Educação pela Pontifícia Universidade Católica de São Paulo. Professora Adjunta do Centro de Educação da Universidade Federal de Alagoas - Campus A. C. Simões, Maceió/Alagoas. Brasil. vianamota@gmail.com

\begin{abstract}
Resumo: Este estudo tem como objetivo compreender o papel da equipe gestora no desenvolvimento e implementação as práticas pedagógicas utilizando as Tecnologias da Informação e Comunicação (TIC) como recurso na escola. A abordagem qualitativa foi a metodologia utilizada e como técnica de coleta de dados a entrevista semiestruturada. Como resultados apontam-se: a) a formação dos professores e gestores necessita de incentivos para o uso das TIC; b) os profissionais participantes do estudo têm uma visão significativa sobre a prática pedagógica mediada pelas tecnologias; c) os gestores necessitam de maiores atitudes para a consolidação de estratégias pedagógicas com uso das TIC; d) é no âmbito da escola pública que a formação continuada deve acontecer para que, juntos, estabeleçam melhorias na ação educativa e, por fim, e) são necessários maiores investimentos do Estado em meio às políticas públicas educacionais, para a consolidação de um ensino de boa qualidade.
\end{abstract}

Palavras-chave: Tecnologia na educação. Gestor escolar. Práticas pedagógicas.

Abstract: This study aims to understand the role of the management team in the development and implementation of pedagogical practices using Information and Communication Technologies (ICT) as a resource in school. The qualitative approach was the methodology used and as data collection technique the semi-structured interview. The results show: a) the training of teachers and managers needs incentives for the use of ICT; b) the professionals participating in the study have a significant view on the pedagogical practice mediated by the technologies; c) managers need greater attitudes for the consolidation of pedagogical strategies using ICT; d) it is within the scope of the public school that continuing education must take place so that, together, they establish improvements in educational action, and finally, e) greater investments of the State are necessary in the context of public educational policies, for the consolidation of education of good quality.

Keywords: Technology in education. School Manager. Pedagogical practices. 


\section{Introdução}

A inserção das Tecnologias da Informação e Comunicação (TIC) no contexto da escola pública é um desafio presente na maioria das realidades educacionais. O desenvolvimento das práticas educativas que direcionam para o êxito do uso didático pedagógico das tecnologias na escola é um mecanismo necessário para o satisfatório trabalho dos docentes e discentes. Em meio ao uso das tecnologias na escola, surgem diversos desafios, os quais são de competência do Estado, dos docentes e da equipe gestora. Assim, o presente estudo foi desenvolvido a partir de uma discussão sobre a equipe gestora e suas contribuições para o processo de implementação das TIC no contexto da escola.

Nessa dimensão, as reflexões seguem com discussões na área da gestão escolar (papel da equipe gestora) e da tecnologia na escola, tendo como ponto de partida a relevância do envolvimento de todos os profissionais da educação para a concretização de uma escola pública de boa qualidade. O trabalho aponta reflexão para todos os educadores, especialmente para os gestores e os coordenadores pedagógicos que são responsáveis pela organização e gestão dos processos educativos no contexto da escola, assim como para a comunidade acadêmica que se debruça sobre estudos com ênfase na gestão escolar compartilhada e tecnologias na educação.

A viabilização de estratégias para o uso das tecnologias na escola perpassa por vários fatores, destacando-se a formação do docente, a estrutura escolar, as políticas públicas e as contribuições da gestão escolar para concretização de uma prática pedagógica mediada pelas TIC. Desse modo, a equipe gestora tem um significativo papel na efetivação e na consolidação de ações que proporcionem oportunidades de caráter inovador e dinâmico. É relevante que o Projeto Político-Pedagógico (PPP) da escola faça referência ao uso das tecnologias, uma vez que é necessário para a efetivação de uma educação democrática, inclusiva e com qualidade social. A vivência dos objetivos estabelecidos no PPP da escola, de forma interativa, possibilita a inovação das posturas educativas de todos os profissionais, assim como a concretização do papel da equipe gestora a fim de consolidar ações favoráveis ao desenvolvimento das práticas escolares.

Com o advento das tecnologias, da internet e das redes sociais, a escola tem um importante papel em contribuir para a interação desses mecanismos com os educandos a partir do processo pedagógico. No entanto, essa interação não se dará de modo fácil e repentino, sendo necessário que todos que formam a escola comprometam-se com a dinâmica estabelecida no cenário escolar, destacando-se, nesse processo, a equipe gestora. Nessa perspectiva, o artigo ora apresentado tem como problemática: Qual é o papel da equipe gestora como mediadora das práticas pedagógicas com o uso das TIC na escola?

Nesse sentido, este estudo apresentou como objetivo geral compreender o papel da 
equipe gestora no desenvolvimento e na implementação nas práticas pedagógicas utilizando as TIC como recurso inovador na escola. Para o alcance desse objetivo foram realizadas algumas ações, dentre elas: a identificação do papel da equipe gestora na escola; a apreciação da importância das tecnologias como recurso pedagógico na contemporaneidade e a apresentação das possíveis ações da equipe gestora e dos demais segmentos da escola para implementação das TIC no cotidiano escolar.

O texto está estruturado em quatro partes que se completam, além da introdução e das considerações finais. $\mathrm{Na}$ primeira são abordadas as tecnologias educacionais e as mudanças ocorridas no paradigma educacional por meio das transformações advindas do processo da globalização. $\mathrm{Na}$ segunda parte, discutem-se as novas tecnologias como mecanismos didáticos para o cenário escolar, ocasionando, dessa forma, mudanças no contexto da escola e nas relações estabelecidas entre os diferentes atores. Na terceira, evidencia-se a gestão escolar como uma importante dimensão para as mudanças de paradigma e inserção das TIC nas práticas pedagógicas da escola. Na quarta e última parte, apresentam-se os resultados da pesquisa desenvolvida em uma escola pública no município de Messias, no estado de Alagoas.

\section{As tecnologias na educação e os novos paradigmas educacionais}

Com o advento da globalização, a sociedade passou por diversas mudanças nas esferas social, cultural, econômica e educacional. A educação, por sua vez, sendo parte integrante da sociedade, também foi uma das dimensões sociais que passam por novos paradigmas e concepções que direcionaram para mudanças pedagógicas e administrativas no cenário escolar. Nesse sentido, a "educação como um todo e o trabalho docente, em especial, estão sendo reconfigurados" (BARRETO, 2004, p. 1182). A reconfiguração de novas práticas surge com as mudanças estabelecidas por meio da globalização e da disseminação das tecnologias na sociedade, destacando-se a escola.

O uso das tecnologias no contexto escolar viabiliza estratégias de conhecimento de caráter inovador, uma vez que os sujeitos do processo educativo podem interagir a partir de diferentes fontes de informação e consolidar uma interação no processo de formação, proporcionando uma significativa troca de conhecimento em uma perspectiva democrática. Barreto (2004, p. 1183) menciona que: 
A presença das TIC tem sido investida de sentidos múltiplos, que vão da alternativa de ultrapassagem dos limites postos pelas "velhas tecnologias", representadas principalmente por quadro-de-giz e materiais impressos, à resposta para os mais diversos problemas educacionais ou até mesmo para questões socioeconômicopolíticas.

A partir do desenvolvimento da globalização, foram sendo encorpados novos recursos pedagógicos, os quais possibilitaram rompimento parcial de metodologias desenvolvidas durante muito tempo. O fato é que, por meio da globalização, as mudanças ocorridas no âmbito escolar significaram em todas as dimensões educativas, inclusive nas políticas educacionais em meio aos programas e projetos elaborados com propósitos de romper com modelos conservadores.

O século XXI possibilitou diversas mudanças no contexto educacional, as quais contribuíram para o aprimoramento das práticas educativas dos docentes, gestores, profissionais da educação e da comunidade da qual a escola faz parte. Em meio a essas mudanças, destaca-se, em especial, a inserção das tecnologias na escola, sendo estas gradativamente inseridas no âmbito escolar. O rádio, a TV, as multimídias, o computador, a internet, as redes sociais, enfim, são diversas as possibilidades de inserção das tecnologias no espaço educativo (LIMA, 2008).

A defesa das TIC no espaço educativo é, por excelência, positiva, uma vez que são ações que favorecem a existência de um pensamento sobre educação diferenciado, caracterizando-se em inovação, interatividade e criatividade. Estudos (REIS, 2014; CARVALHO; SILVA, 2014; SALES; BARBOSA; SANTANA, 2014) apontam que a tecnologia como recurso pedagógico contribui satisfatoriamente para o processo de aprendizagem dos sujeitos envolvidos, configurando-se em uma aprendizagem moderna e significativa.

Nesse contexto, os gestores escolares têm um papel relevante para a concretização de um ensino voltado às perspectivas atuais da sociedade e da educação, uma vez que são responsáveis pela organização pedagógica e administrativa da escola, pela interação entre escola e sociedade, e articuladores da vivência participativa no contexto escolar.

\section{As novas tecnologias da informação e comunicação no espaço escolar}

A educação é um processo social que necessita estar em constante mudança em virtude dos aspectos sociais, culturais, econômicos e políticos que são estabelecidos nas práticas sociais. Desse modo, as posturas pedagógicas também carecem de mudanças, as quais normatizam diferentes experiências, contextos e situações vivenciadas no âmbito sócio-educacional.

A interação das tecnologias no cenário escolar modificou as práticas pedagógicas, dimensionando para rupturas significativas no processo de ensino e aprendizagem. Com a adesão das TIC no contexto escolar/social, os discentes são envolvidos para uma dimensão educativa 
que viabiliza novas estratégias de comunicação, interação e aprendizagem, configurando alternativas comuns de aprendizagem. De acordo com Porto (2006, p. 54), as TIC "possibilitam ao indivíduo ter acesso a uma ampla gama de informações e complexidades de um contexto (próximo ou distante) que, num processo educativo, pode servir como elemento de aprendizagem, como espaço de socialização, gerando saberes e conhecimentos científicos”.

A interação dos alunos com os aparelhos tecnológicos viabiliza novos conhecimentos, rompendo com espaço, tempo e culturas. A aprendizagem torna-se, nessa lógica, um mecanismo democrático com possibilidades de inovação e relevância social. $O$ desafio de vivenciar experiências educativas no contexto escolar, no processo de ensino e aprendizagem, é um importante artefato a ser resolvido como estratégia para superar os embates pedagógicos, as posturas educacionais e as problemáticas que existem no cotidiano escolar.

É pertinente fazer com que o espaço escolar seja reconfigurado com novas linguagens, incluindo a tecnológica, como recurso inovador, provocador e significativo para as interações e descobertas. Nessa dimensão, consolidar conhecimentos com as TIC é um processo peculiar, porém necessário diante do cenário político, social e cultural que a sociedade globalizada vivencia. Assim, segundo Porto (2006, p.45),

[...] muitas escolas não estão abertas para a incorporação, ou, quem sabe, para o desafio de um trabalho com essas linguagens em seus cotidianos. Diante dessas linguagens, a grande maioria dos docentes (ou mesmo pais) se vê apenas como usuário/telespectador. A preparação social e/ou pedagógica para seu uso não é, na maioria das vezes, cogitada.

Com efeito, a prática pedagógica é o caminho para as possíveis mudanças ocasionadas no processo de ensino e de aprendizagem por meio das TIC, sendo um mecanismo de descoberta para a apropriação de estratégias cotidianas no cenário escolar. Cabe destacar que o envolvimento das tecnologias no processo de ensino e aprendizagem pressupõe novos paradigmas, sendo uma inovação para os envolvidos no processo de interação social. Desse modo, é necessário que a equipe escolar esteja envolvida para superar os desafios e possibilitar um efetivo uso das tecnologias que a escola tem, assim como conceba os recursos tecnológicos como mecanismos pedagógicos apropriados para as mudanças sócio-educacionais presentes no cenário atual.

A forma como as tecnologias estão sendo administradas e organizadas no cenário escolar viabiliza um diferencial nas práticas educativas. A utilização satisfatória dos recursos tecnológicos, mesmo que poucos, é importante para a apropriação do saber com diferentes estratégias educacionais. Almeida (2009, p. 76) afirma que "gradativamente as tecnologias são introduzidas nos espaços das escolas, mas, mesmo quando há utilização adequada, os equipamentos se encontram confinados em salas isoladas ou trancados em laboratórios, em quantidade 
insuficiente para atender todos os alunos".

Dessa forma, a equipe gestora tem um significativo papel em contribuir para o uso de modo apropriado das tecnologias no contexto escolar. A organização dos espaços em que se pode trabalhar com os recursos tecnológicos, os profissionais responsáveis pelas atividades, assim como formações continuadas para os profissionais, são relevantes ações para viabilizar alternativas no desenvolvimento e no uso das tecnologias na escola. Para Almeida (2009, p. 78), as tecnologias:

\footnotetext{
São elementos relevantes do contexto que reconfiguram a situação e criam possibilidades diferentes para o ensino e a aprendizagem, uma vez que, além da expressão material de instrumentos, englobam as dimensões técnica, social e cultural envolvidas em sua produção, expandem o potencial humano e propiciam que, através da Internet, alunos, professores e membros da comunidade, situados em diferentes territórios, possam compartilhar experiências educativas centradas nas relações que se estabelecem em contexto virtual.
}

O uso das tecnologias no contexto escolar dimensiona a aprendizagem para vários espaços sociais, os quais contribuem para a divulgação dos trabalhos desenvolvidos, valorizando os diferentes profissionais e a própria comunidade que fizeram parte das atividades realizadas. Nesse sentido, os envolvidos são agentes do processo educativo, condicionando para a vivência de uma gestão compartilhada e significativa.

Para Almeida (2009), a escola deve ser um fórum aberto de aprendizagem por meio da divulgação via rede dos projetos e das vivências estabelecidas na escola. Informa ainda que as dimensões cultural, social e técnica são aspectos que precisam ser aprimorados no cenário escolar, tendo como objetivo aproximar os diferentes segmentos na vivência de experiências coletivas. Contribuir para uma escola democrática, inclusiva e com qualidade social é papel de todos, sendo relevante que a equipe gestora, a partir das experiências vivenciadas pela comunidade escolar, possibilite uma significativa relação entre ensino, aprendizagem e comunidade local, mediante as novas posturas educacionais presentes no contexto social.

\section{A gestão escolar e as TIC no cenário educativo}

O espaço escolar é composto por diversas pessoas e culturas que contribuem para o desenvolvimento das atividades e dos projetos realizados pela instituição. Nesse sentido, "as organizações de trabalho hoje são vistas como sistemas vivos. Concebê-las como redes dinâmicas e não lineares pode dar uma ideia de sua complexidade, já que o paradigma mecanicista não é mais suficiente para explicá-las” (HESSEL, 2004, p. 2). Compreender a organização escolar como espaço dinâmico para as mudanças sociais e educacionais é um aspecto relevante para a gestão 
escolar, que tem como princípio a participação de todos no processo de ensino e gestão da escola pública.

Em meio aos desafios vivenciados pelos gestores na escola, destaca-se, diante das exigências e mudanças sociais, o uso das tecnologias como recurso pedagógico e dimensão da aprendizagem significativa, uma vez que a interação, a informação e a conexão do mundo possibilitam um processo de ensino e aprendizagem pertinente para a concepção de educação defendida no século XXI. Assim, "o gestor escolar lida, hoje, com desafios decorrentes da mudança de paradigmas sociais, econômicos e políticos, que pautam uma nova forma de pensar e fazer a gestão da escola" (VALLIN; RUBIM, 2007, p. 86). Desse modo, cabe ao gestor e à sua equipe pedagógica favorecer condições para que o ensino mediado pelas tecnologias esteja presente no currículo, no PPP, nas atividades pedagógicas e nas aprendizagens cotidianas. Entretanto, segundo Hessel (2004, p.3),

[...] os gestores, mesmo os familiarizados com a tecnologia, ainda restringem a sua atenção para a disseminação do uso do computador como ferramenta ou tecnologia de suporte para o trabalho docente, mais especificamente para as questões de ensino e aprendizagem. Geralmente os esforços e recursos são prioritariamente direcionados para a criação e manutenção dos laboratórios de informática no interior da escola

A partir dos argumentos de Hessel (2004), pode-se compreender que o processo de ensino e de aprendizagem mediado pelas TIC ultrapassa os laboratórios de informática e supera as tradicionais tecnologias presentes no contexto escolar (TV, vídeo, rádio). É oportuno pensar em projetos inovadores para a valorização das TIC no processo pedagógico e na valorização das exigências educacionais na contemporaneidade. De acordo com a autora, "ensinar e aprender não se limitam ao trabalho dentro da sala de aula, mas implicam modificar o que fazemos dentro e fora dela, organizar ações de pesquisa e comunicação, através da Internet, recebendo e enviando mensagens, discutindo questões em fóruns, etc.” (HESSEL, 2004, p. 4).

O uso das TIC não se reduz ao processo de assimilação de estratégias didáticas para o ensino e aprendizagem, da pesquisa e da interação entre estudantes e conhecimento. As novas tecnologias são suportes para ampliar os canais da comunicação, nos contextos interno e externo, visto que a divulgação das atividades e projetos para a comunidade, à qual a escola pertence, é um mecanismo necessário para a interação entre escola, pais e comunidade. Esse aspecto pedagógico proporcionado pelas TIC é favorável para o processo de compartilhamento de informações, uma vez que todos percebem os resultados dos trabalhos desenvolvidos na instituição (HESSEL, 2004). Desse modo, na visão de Hessel (2004, p. 5): 
As TIC podem dar suporte para a comunicação entre os elementos da escola, pais, comunidade e outros organismos. Pode ajudar na realização de atividades colaborativas que se propõem a enfrentar problemas locais ou desenvolver projetos inovadores para ampliar e modernizar a gestão administrativa e pedagógica na escola. Nesse sentido, algumas escolas estão construindo seu site para publicar seus projetos na Internet e ativar canais de comunicação.

A interação entre escola e comunidade, mediada pela internet e redes sociais, torna-se um aspecto peculiar na concretização de um espaço dinâmico e inovador. A equipe pedagógica da escola tem o papel de possibilitar que a comunidade local tenha acesso aos diversos trabalhos desenvolvidos, por meio da divulgação dos resultados e das diversas redes que existem e fazem parte do cotidiano de muitos que compõem o espaço escolar interno e externo.

Estudos de Alonso (2007); Bulhões, Oliveira, (2012); Carvalho, Silva, (2014) apontam que o uso das TIC no contexto escolar pelos gestores também evidencia a prática pedagógica, destacando a relação entre o fazer pedagógico e o administrativo, mediante a interação das tecnologias da informação e comunicação. Nessa perspectiva, os gestores têm o papel de possibilitar que diferentes estratégias sejam vivenciadas no âmbito da escola, a fim de contribuir com o processo de ensino e aprendizagem por meio das TIC. Assim, "O gestor deve ser preparado para usar os recursos tecnológicos na gestão e no cotidiano escolar, adquirindo condições de orientar e de desencadear situações, as quais estimulem o uso dessas ferramentas por toda comunidade escolar de forma criativa" (TERÇARIOL; SIDERICOUDES, 2007, p. 56).

Desse modo, a atuação e o envolvimento que os gestores têm com as TIC possibilitam que diferentes aspectos sejam abordados com o uso das tecnologias no interior da escola, destacando-se a organização escolar administrativa e pedagógica e a interação escola-paiscomunidade. Alonso (2007) aponta que a tecnologia é um instrumento favorável para concretizar mudanças na escola e para contribuir com o gestor na organização do processo acadêmico, favorecendo um espaço inovador, dinâmico e interativo entre todos os envolvidos no processo educativo.

\section{Conhecendo uma realidade...}

A pesquisa foi desenvolvida por meio de uma abordagem qualitativa. No que se refere aos métodos de pesquisa, foi utilizado o estudo de caso. De acordo com Severino (2007), a pesquisa qualitativa contribui na compreensão das categorias já analisadas por pesquisadores e reflete-as de modo que possa ter uma maior referência sobre as discussões apresentadas.

Inicialmente foram realizados estudos bibliográficos, os quais contribuíram para a compreensão dos principais aspectos que norteiam uma escola pública com perspectivas de 
inovação por meio das tecnologias. Como coleta de dados, a entrevista semiestruturada foi necessária para conversarmos com alguns funcionários da instituição e, como análise dos dados, utilizamos a análise do conteúdo, na perspectiva de Bardin (2002), tendo como categorias de análise: tecnologias na escola, equipe gestora e formação de professores. Estas foram destacadas após a coleta de dados, pois foram as principais evidências para uma significativa análise e discussão dos resultados.

O estudo foi desenvolvido em uma escola pública da rede municipal da cidade de Messias, no estado de Alagoas, considerada de pequeno porte, tendo 6 (seis) salas de aula, funcionando nos três turnos com turmas do $1^{\circ}$ ao $5^{\circ}$ ano e EJA. Atualmente tem 405 alunos. A gestão da instituição é composta por uma diretora geral e três coordenadoras pedagógicas, sendo uma em cada turno.

A pesquisa foi desenvolvida com duas professoras que aceitaram contribuir com o estudo, uma coordenadora e a gestora escolar. As entrevistas foram realizadas na própria escola, individualmente, de acordo com a disponibilidade de cada participante. A coleta de dados foi desenvolvida a partir de quatro visitas à instituição, sendo a primeira para estabelecer contatos e as demais para a coleta dos dados e conhecimento da realidade referente à discussão em análise.

As categorias foram instrumentos importantes na construção do material para a análise dos dados. Desse modo, tecnologias na escola, equipe gestora e formação de professores são os referenciais para a discussão desenvolvida a partir dos resultados encontrados na pesquisa.

\section{a) Tecnologias na escola}

O papel da equipe gestora na prática pedagógica com uso das TIC na escola, cujo estudo foi realizado, apresenta problemáticas. A instituição dispõe de alguns equipamentos tecnológicos, os quais contribuem para a prática docente e a inovação dessa ação no cotidiano escolar. De acordo com os atores envolvidos na pesquisa, é necessária maior interação entre a postura pedagógica de todos os profissionais e as tecnologias como recurso mediador para mudanças no processo de ensino e aprendizagem. A professora I apresentou sua visão sobre o uso das tecnologias no contexto escolar: "geralmente, no planejamento, temos a iniciativa de colocar trabalhos para serem desenvolvidos no laboratório. Os alunos fazem pesquisa sobre alguns temas, vão digitar algum trabalho, ou até mesmo para jogar. Porque nos computadores têm uns jogos que são muito bons para as crianças brincarem. Gosto muito de levar os alunos para lá, mas tem um grande problema. Como só são 15 (quinze) computadores, os alunos brigam para ficar no computador, aí coloco em dupla e, cada vez, um aluno vai conduzindo as atividades" (Professora 1). 
De acordo com a professora I, o espaço escolar destinado às aulas nos laboratórios de informática não contribui para o desenvolvimento de atividades educativas com uso das TIC. No entanto, a mesma professora relatou que, no ambiente educativo, é possível encontrar TV, DVD, máquina de xerox como recursos à disposição para o desenvolvimento do trabalho educativo. Desse modo, pode-se recorrer ao posicionamento de Carvalho e Silva (2014), os quais afirmam que, para muitos educadores, o trabalho com tecnologias refere-se apenas ao laboratório de informática. São várias as estratégias e os mecanismos que se podem vivenciar na prática pedagógica, mediada com as TIC. Diante dessa situação, é possível perceber que o desenvolvimento de estratégias significativas e inovadoras depende da formação inicial e continuada dos professores, sendo essa dimensão um importante aspecto para ser problematizado.

Outra questão relevante, que ficou evidenciada a partir dos resultados, foi a visão que os professores têm da relevância das tecnologias. Todos os participantes evidenciaram, em seus depoimentos, que as tecnologias da informação e comunicação são instrumentos significativos para a aprendizagem, possibilitam inovação, criatividade e interação, e, especialmente, a professora II mostrou sua visão, quando apontou: "vivemos no mundo em que tudo é globalizado e as escolas também deveriam ter condições de oferecer um trabalho, mesmo que mínimo, com os alunos. Até porque a nossa demanda de alunos é muito carente. Eles não têm computadores em casa, então aqui, deveria ter uma estrutura para ajudar esses alunos a pesquisar, digitar textos, enfim, perceber o mundo da tecnologia" (Professora II). Cabe destacar a relevância que o letramento digital tem no cenário da escola, isso porque a maioria dos estudantes da escola pública não tem acesso a essas tecnologias em suas residências, sendo necessária uma maior consideração das propostas educacionais sobre esse aspecto.

Nesse sentido, a professora deixou explícita sua percepção acerca da importância do letramento digital, uma vez que as configurações políticas, sociais e culturais demandam essa prática. Araújo (2007) destaca que o desafio de proporcionar uma educação de boa qualidade está em contribuir na formação de sujeitos críticos, reflexivos, criativos, conscientes de seus papeis, tornando-se verdadeiros cidadãos autônomos e participativos, que saibam viver e conviver com o coletivo. Uma das principais estratégias para a conquista desses objetivos é a vivência de um ensino no qual possibilite uma integração entre educação e tecnologias.

A professora II destacou também a realidade dos estudantes, ou seja, o local no qual estão inseridos, como uma dimensão satisfatória para que a escola, enquanto instituição social, possa cumprir sua função que é possibilitar aos seus participantes apropriarem-se efetivamente das situações políticas, culturais e sociais, viabilizando a construção de novos conhecimentos e 
mudanças nas atitudes cotidianas. Essa ação é possível mediante uma prática escolar que coloque os interesses dos estudantes no centro do processo pedagógico e as propostas sejam desenvolvidas na perspectiva da inovação e comunicação.

\section{b) Equipe gestora}

Para a coordenadora pedagógica, a escola vivencia alguns entraves que prejudicam o envolvimento satisfatório do uso das tecnologias como recurso didático e pedagógico. A profissional apontou que a formação dos professores que não contribui para o sucesso do processo pedagógico, assim como a estrutura da escola, mas retomou à mesma discussão da professora I. Mais uma vez, percebe-se o laboratório de informática como principal instrumento para o trabalho pedagógico. A coordenadora apontou: "eu vejo que nós tentamos de todas as formas fazer com que os professores usem as tecnologias que temos disponíveis. No entanto, temos resistências de alguns e também os desafios que são presentes. Como, por exemplo, o laboratório que é improvisado, são poucos computadores, nem todos acessam a internet. Enfim, são muitos os entraves, mas podemos pouco a pouco fazer um trabalho diferenciado" (Coordenadora).

A partir do depoimento da coordenadora, é possível estabelecer algumas reflexões oportunas sobre o papel da equipe gestora, direção e coordenação nas propostas pedagógicas. O principal aspecto é sobre a resistência dos docentes para o trabalho com uso das TIC. Diante dessa questão, a reflexão permeia no seguinte questionamento: Quais as estratégias que os gestores vivenciam para contribuir com a formação dos docentes no uso das TIC e no incentivo às propostas inovadoras? Cabe à equipe gestora viabilizar formação continuada, convidar especialistas para favorecer oportunidades as quais dimensionem inovação, criatividade e interação nas propostas pedagógicas dos professores. De acordo com Alonso (2007), os gestores têm o compromisso de elaborar projetos juntamente com a comunidade escolar para construírem um espaço de aprendizagem e vivência coletiva.

A gestora da instituição foco do estudo destacou que as mudanças devem acontecer sistematicamente no planejamento do docente, mencionou ainda que a formação do professor e a realidade da escola pública interferem no trabalho cotidiano no tocante ao uso das tecnologias. A profissional tem a percepção de que o trabalho pedagógico deve ser desenvolvido pelos coordenadores e professores. Desse modo, a gestora afirmou: "os coordenadores pedagógicos sempre destacam que é bom tentar mudar as aulas, fazer trabalhos no laboratório de informática. Isso tudo que está aqui é da escola, então temos que usar, mas acredito que ainda falta muito para chegarmos ao ponto ideal da tecnologia na escola, principalmente, a escola pública” (Gestora). 
Em conversas com a gestora da escola, ficou evidenciado que ela tem a visão de que, na atualidade, não se concebe uma escola com práticas pedagógicas conservadoras, assim como as tecnologias são essenciais para a mudança de paradigma educacional. No entanto, a profissional também deixou transparecer que esse papel é exclusivo dos coordenadores e professores. Nessa perspectiva, Libâneo (2004) aponta que a escola é uma dimensão social composta por diversos segmentos e todos têm o compromisso para a sua melhoria. Assim, é possível afirmar que a inserção das tecnologias no contexto escolar é papel de todos os envolvidos, e o gestor tem uma significativa parcela para o sucesso dessa ação no contexto escolar. De acordo com a gestora da instituição escolar, "a tecnologia na sala de aula contribui para o processo de desenvolvimento dos alunos. Com a efetivação das tecnologias na sala de aula, todos ganham. Por isso, que sempre destacamos que é bom inovar, fazer diferente, mas o que dificulta são as dificuldades" (Gestora).

A gestora compreende a ação favorável que as TIC oferecem na proposta pedagógica, assim como a aceitação que os estudantes têm diante dos trabalhos desenvolvidos com uso das TIC, mas falta mais atitude para a efetivação da inovação apontada pela profissional. A coordenadora pedagógica acredita que o primeiro aspecto para a mudança na escola é o envolvimento de todos para o compromisso da inovação pedagógica com uso das TIC.

Para Alonso (2007), não haverá sucesso nas práticas educacionais se não existir um grande projeto, no qual todos os profissionais estejam envolvidos, possibilitando compromisso, estudos coletivos e disposição para melhorias nas ações educativas. Diante da vivência dos aspectos destacados pela autora, os desafios existirão, no entanto, o compartilhamento dos problemas proporcionará soluções satisfatórias. Cabe salientar, ainda, a importância das TIC no currículo, no planejamento e nas políticas desenvolvidas e vivenciadas no contexto das atividades educacionais.

\section{c) Formação de professores}

Os profissionais da escola foco do estudo salientaram que os maiores desafios vivenciados no contexto da instituição são a formação dos professores e a estrutura física. A coordenadora pedagógica apontou que: "vejo que o principal desafio é a formação dos professores. Porque são muitas as estratégias que podemos utilizar como um vídeo, um filme, uma pesquisa, mas poucos fazem isso. $\mathrm{Na}$ verdade, o espaço poderia ser melhor, mas é o que temos, então vamos fazer a nossa parte" (Coordenadora).

Diante do depoimento da coordenadora, percebe-se uma contradição, especialmente, porque a função do coordenador é contribuir na formação dos professores. Nesse sentido, questiona-se: por que os gestores não contribuem na formação dos profissionais para 
aprimorarem a prática pedagógica com uso das TIC? Libâneo (2004) salienta que a principal função do coordenador pedagógico é favorecer apoio à prática educativa, especialmente, pela formação continuada na própria escola. A fala da coordenadora deixou explícita que o vídeo, o filme, as pesquisas são estratégias que favorecem o ensino e aprimoram os trabalhos educativos desenvolvidos com os estudantes.

A gestora da instituição tem a mesma percepção da coordenadora pedagógica. Ela destacou que a formação continuada é um desafio para o aprimoramento das questões educativas, no entanto não faz nenhuma alusão ao seu papel enquanto gestora e responsável pelo desempenho das questões pedagógicas. Ela destacou que: "falta muita coisa. Desde a estrutura física da escola, os equipamentos e a própria formação dos professores. Eles, na verdade, não estão preparados para trabalhar com as tecnologias de forma inovadora, de modo que atraia os estudantes. No ano passado, tinha uma professora que pegava a televisão duas ou três vezes por semana, mas apenas para colocar os alunos para assistir filmes, sem objetivo nenhum. Por esse caso, podemos ver que há uma defasagem na formação do professor ainda” (Gestora).

A partir do depoimento da gestora, pode-se ampliar a visão sobre a defasagem da formação dos professores, acrescentando que a formação dos próprios gestores também necessita de uma inovação. De acordo com Alonso (2007), ao gestor escolar cabe possibilitar que os professores tenham condições de trabalhar dentro das suas possibilidades e não apenas apontar os equívocos dos docentes, sem apresentar nenhuma contribuição. Nessa perspectiva, é necessário diagnosticar que as condições de um significativo trabalho com as TIC não dependem apenas das questões de formação e condições estruturais da instituição, mas de dimensões políticas e culturais. Esse aspecto é apontado pela professora II quando destacou os desafios encontrados para desenvolver um trabalho com as TIC no âmbito da escola: "aqui, eu acredito, que seja o espaço. Pois seria muito bom se tivesse espaço para todas as crianças e, principalmente, internet em todos os computadores. Outra questão, temos um Datashow, mas não temos um notebook. Se a gente quiser trabalhar com slides, vídeos ou outra questão, temos que trazer, de casa, o nosso computador" (Professora II).

O depoimento da professora evidenciou questões já refletidas, mas destacou um novo mecanismo que merece atenção: o investimento na educação para uma qualidade no ensino e nas práticas pedagógicas. As tecnologias fazem parte da realidade da sociedade, mediante a globalização e a informação. Desse modo, não se concebe uma escola pública sem ter equipamentos tecnológicos mínimos para o desenvolvimento das atividades básicas como apresentação de slides, filmes, vídeos, enfim, é necessário maior investimento nas escolas públicas para viabilizar oportunidades de melhorias nas condições de ensino no contexto educacional (LIBÂNEO, 2004). 


\section{Considerações Finais}

A educação como mecanismo de mudança política, social e cultural necessita de significativas rupturas para proporcionar aos seus agentes resultados satisfatórios e contemporâneos. Os resultados do estudo possibilitaram refletir sobre questões que estão postas nas escolas públicas, especialmente, a formação continuada dos docentes e gestores, sendo estes últimos os sujeitos que têm relevância na organização das práticas pedagógica, administrativa e financeira no contexto educativo.

A formação continuada como estratégia inovadora e significativa com uso das TIC é o principal aspecto destacado pelos participantes, uma vez que a educação contemporânea necessita de novos modelos, concepções e metodologias. Ficou evidenciado, também, que cabe aos gestores (coordenador e gestor) proporcionar formação continuada, reconfigurando-se a prática pedagógica e possibilitando maiores oportunidades na função social da educação.

Diante da questão central do artigo, pode-se evidenciar que, na escola pública foco da análise, os gestores têm uma visão significativa da importância das TIC no contexto escolar e para o sucesso da aprendizagem e da inovação pedagógica. No entanto, essa dimensão fica apenas na teoria, uma vez que esses profissionais não desenvolveram nenhum trabalho pertinente para a consolidação das TIC na prática educativa dos docentes, gerando, assim, uma contradição entre a reflexão e a ação.

Em síntese, os principais resultados apontaram que: a) a formação dos professores e gestores necessita de incentivos para o uso das TIC; b) os profissionais participantes do estudo têm uma visão significativa sobre a prática pedagógica mediada pelas tecnologias; c) os gestores necessitam de maiores atitudes para a consolidação de estratégias pedagógicas com uso das TIC; d) é no âmbito da escola pública que a formação continuada deve acontecer para que juntos estabeleçam melhorias na ação educativa e, e) são necessários maiores investimentos do Estado em meio às políticas públicas educacionais para a consolidação de um ensino de boa qualidade.

Os professores destacaram que os desafios postos para o significativo trabalho estão, especialmente, no espaço restrito dos laboratórios de informática, não tendo uma visão ampla das múltiplas possibilidades das estratégias viabilizadas com as inúmeras tecnologias a favor da ação pedagógica. Por fim, ficou evidenciado que se necessita de maiores investimentos para a melhoria da qualidade da educação, assim como para o acesso às tecnologias básicas no âmbito escolar como Datashow, notebook, microfones, caixas de som, micro system, TV, DVD, entre outros recursos necessários à escola para o desenvolvimento das atividades com o uso das TIC. Eis, portanto, o desafio! 


\section{Referências}

ALMEIDA, Maria E. Gestão de tecnologias, mídias e recursos na escola: o compartilhar de significados. Em Aberto, Brasília, v. 22, n. 79, p. 75-89, jan. 2009.

ALONSO, Myrtes. Formação de gestores escolares: um campo de pesquisa a ser explorado. In: ALMEIDA, Maria Elizabeth Bianconcine de; ALONSO, Myrtes. Tecnologias na Formação e na gestão escolar. São Paulo: Avercamp, 2007.

ARAÚJO, Maria I. Incorporação das tecnologias de informação e comunicação na escola pública. In: MERCADO, Luís P. (Org.). Percursos na formação de professores com tecnologias da informação e comunicação na educaşão. Maceió: EDUFAL, 2007.

BARDIN, Laurence. Análise de conteúdo. Lisboa: Edições 70, 2002.

BARRETO, Raquel G. Tecnologia e educação: trabalho e formação docente. Educação \& Sociedade, Campinas, v. 25, n. 89, p. 1181-1201, set./dez. 2004.

BULHÕES, Gilvanilda V.; OLIVEIRA, Carmem L. Possibilidades e limites do uso de tecnologias da informação e comunicação nas escolas públicas estaduais: o papel do gestor escolar. In: MERCADO, Luis P. (Org.). Integração e gestão de mídias na escola. Maceió: EDUFAL, 2012.

CARVALHO, Artemis B.; SILVA, Dakson K. O uso das TIC na educação: desafios e perspectivas para o professor. Anais...Colóquio "Educação e Contemporaneidade", São Cristóvão-SE, 8, 2014.

HESSEL, Ana M. As TIC podem auxiliar na gestão da escola? São Paulo: Pontifícia Universidade Católica de São Paulo, 2004.

LIBÂNEO, José C. Organização e gestão da escola: teoria e prática. Goiânia: Alternativa, 2004.

LIMA, Fabíola da C. Gestão escolar hoje: a cultura tecnológica no espaço escolar. Maranhão: Universidade Estadual do Maranhão, 2008.

PORTO, Tania M. As tecnologias de comunicação e informação na escola: relações possíveis... relações construídas. Revista Brasileira de Educação, v. 11, n. 31, jan./abr. 2006.

REIS, Anderson A. As TICs como recursos complementares de ensino: a formação de professores frentes às novas tecnologias. Anais... Colóquio "Educação e Contemporaneidade", São Cristóvão-SE, 8, 2014.

SALES, Karine M.; BARBOSA, Mônica de Gois Silva; SANTANA, Karine Gois da Paixão. Tecnologias e educação: desafios e possibilidades no espaço escolar. Anais... Colóquio "Educação e Contemporaneidade", São Cristóvão-SE, 8, 2014.

SEVERINO, Antônio Joaquim. Metodologia do trabalho científico. São Paulo: Cortez, 2007.

TERÇARIOL, Adriana Aparecida de Lima; SIDERICOUDES, Odete. Potencializando o Uso de Tecnologias na Escola: O papel do gestor. In: ALMEIDA, Maria E.; ALONSO, M. Tecnologias na formação e na gestão escolar. São Paulo: Avercamp, 2007. 
VALLIM, Celso; RUBIM, Lígia C. Articulação administrativa e pedagógica na gestão escolar com o uso de tecnologias. In: ALMEIDA, Maria Elizabeth Bianconcine de; ALONSO, Myrtes.

Tecnologias na formação e na gestão escolar. São Paulo: Avercamp, 2007.

VIEIRA, Paula A. As TIC no apoio à gestão escolar e na interação com a comunidade: estudo de caso numa escola secundária. 2008. Dissertação (Mestrado em Comércio eletrônico e internet). Universidade Aberto: Lisboa, 2008.

Recebido em: 31 maio 2017 / Aprovado em: 02 fev. 2018

\section{Cite como}

SILVA, Givanildo da; VIANA, Maria Aparecida Pereira. As tecnologias na educação: o papel da equipe gestora nas práticas pedagógicas. Dialogia, São Paulo, n. 32, p. 183-198, maio/ago. 2019. Disponível em: https://doi.org/10.5585/Dialogia.n32.7484. 